\title{
Testicular responses to hCG stimulation at varying doses in men with spinal cord injury
}

\author{
WA Bauman ${ }^{1,2,3}$, MF La Fountaine ${ }^{1,2,4}$, CM Cirnigliaro ${ }^{1}$, SC Kirshblum ${ }^{5,6}$ and AM Spungen ${ }^{1,2,3}$
}

Study design: Prospective.

Objectives: To test whether provocative stimulation of the testes identifies men with chronic spinal cord injury (SCI), a population in which serum testosterone concentrations are often depressed, possibly due to gonadal dysfunction. To accomplish this objective, conventional and lower than the conventional doses of human chorionic gonadotropin (hCG) were administered.

Methods: Thirty men with chronic SCl (duration of injury $>1$ year; 18 and 65 years old; 16 eugonadal ( $>12.1 \mathrm{nmol} \mathrm{I}^{-1}$ ) and 14 hypogonadal $\left(\leqslant 12.1 \mathrm{nmol} \mathrm{I}^{-1}\right)$ ) or able-bodied $(A B)$ men (11 eugonadal and 27 hypogonadal) were recruited for the study. Stimulation tests were performed to quantify testicular responses to the intramuscular administration of hCG at three dose concentrations (ithat is, 400, 2000 and 4000 IU). The hCG was administered on two consecutive days, and blood was collected for serum testosterone in the early morning prior to each of the two injections; subjects returned on day 3 for a final blood sample collection.

Results: The average gonadal response in the $\mathrm{SCl}$ and $\mathrm{AB}$ groups to each dose of hCG was not significantly different in the hypogonadal or eugonadal subjects, with the mean serum testosterone concentrations in all groups demonstrating an adequate response.

Conclusions: This work confirmed the absence of primary testicular dysfunction without additional benefit demonstrated of provocative stimulation of the testes with lower than conventional doses of hCG. Our findings support prior work that suggested a secondary testicular dysfunction that occurs in a majority of those with $\mathrm{SCl}$ and depressed serum testosterone concentrations.

Spinal Cord (2017) 55, 659-663; doi:10.1038/sc.2017.8; published online 21 February 2017

\section{INTRODUCTION}

Serum testosterone concentrations have been reported to be depressed in men with chronic spinal cord injury (SCI).${ }^{1-4}$ Depressed levels of testosterone may be associated with infertility but also have a profound effect on body composition, musculoskeletal function and mood. ${ }^{5-8}$ The potential reasons for low levels of testosterone in the SCI population may include chronic illness, stress, nutritional factors and use of centrally acting medications. ${ }^{9-12}$ Primary testicular failure, regardless of the etiology, may be responsible for low levels of circulating testosterone. Determination of whether an appropriate response to gonadal stimulation occurs will provide an answer as to whether the hypogonadism, frequently observed in men with SCI, is primary in origin, or a secondary to pituitary-hypothalamic dysfunction.

In men with SCI, gonadal stimulation to a conventional dose of human chorionic gonadotropin (hCG $4000 \mathrm{IU}$ ) has recently been reported to be associated with a normal gonadal response- that is, an appropriate rise in serum testosterone concentration to provocative stimulation, regardless of whether a subject was classified as being hypogonadal or eugonadal. ${ }^{13}$ Patron et al. ${ }^{14}$ reported that the magnitude of the testosterone response varies directly with the dose of hCG administered; circulating testosterone levels rise with a hCG dose of $375 \mathrm{IU}$ and were maximally stimulated with a dose of $6,000 \mathrm{IU}$, the highest dose administered in this report. It is generally accepted that the dose of hCG to produce maximum testicular stimulation is between 6000 and 10000 IU. $^{14-16}$ Of note, doses of hCG above 2000 IU are associated with pharmacological levels of plasma hCG and result in the Leydig cell being refractory to additional doses of hCG. ${ }^{14,17}$ It may be speculated that the routine clinical test of Leydig cell function that serves to maximally stimulate the testes may not be sufficiently sensitive to identify more subtle forms of testicular dysfunction. In our previous report, ${ }^{13}$ the possibility was hypothesized that a lower dose of hCG would be able to differentiate between those who had lesser degrees of gonadal dysfunction from those who had responded adequately to a conventional dose of hCG. To address this possibility, stimulation of the testes was performed in a conventional manner, as well as with lower doses of hCG, in a cohort of men with chronic SCI.

\section{MATERIALS AND METHODS}

Study cohort

Subjects were recruited from the James J Peters VA Medical Center (JJP VAMC), Bronx, NY, USA and the Kessler Institute of Rehabilitation (KIR),

\footnotetext{
${ }^{1}$ Department of Veterans Affairs Rehabilitation Research \& Development Service National Center for the Medical Consequences of Spinal Cord Injury, James J Peters Veterans Affairs Medical Center, Bronx, NY, USA; ${ }^{2}$ Department of Medicine, Icahn School of Medicine at Mount Sinai, New York, NY, USA; ${ }^{3}$ Department of Rehabilitation Medicine, Icahn School of Medicine at Mount Sinai, New York, NY, USA; ${ }^{4}$ School of Health and Medical Sciences, Seton Hall University, South Orange, NJ, USA; ${ }^{5}$ Kessler Institute for Rehabilitation, West Orange, NJ, USA and ${ }^{6}$ Department of Physical Medicine and Rehabilitation, Rutgers New Jersey Medical School, Newark, NJ, USA

Correspondence: Dr WA Bauman, Department of Veterans Affairs Rehabilitation Research \& Development Service National Center for the Medical Consequences of Spinal Cord Injury, James J Peters VA Medical Center, 130 West Kingsbridge Road, Room 7A-13, Bronx, NY 10468, USA.

E-mail: william.bauman@va.gov

Received 12 October 2016; revised 3 January 2017; accepted 6 January 2017; published online 21 February 2017
} 
West Orange, NJ, USA. Otherwise healthy men, between the ages of 18 and 65 with chronic SCI (duration of injury $>1$ year) or healthy men who were neurologically intact [able-bodied $(\mathrm{AB})]$ were considered for screening for study eligibility. Because the group with SCI was recruited from a convenience sample, and approximately half of the SCI participants were found to have serum testosterone concentrations below the normal range without an apparent etiology for this condition, an effort was made to recruit a similar distribution in the $\mathrm{AB}$ group by randomly screening a convenience sample of individuals for serum testosterone concentration to permit identification of a sufficient number of subjects with low values for enrollment. Exclusion criteria consisted of the following conditions: acute illness; active thyroid disease; medications for depression, mood changes or any nervous system condition; centrally acting high blood pressure medications (that is, guanethidine, reserpine, methyldopa, $\beta$-adrenergic blockers, clonidine and so on.); medications for gastrointestinal disorders; medication for heart disease; medications for seizures (that is, dilantin or barbiturates); epilepsy; congestive heart failure; anti-cancer medications; antibiotics; pain medications; hormones (other than replacement doses); history of pituitary or testicular surgery; and/or less than 18 or older than 65 years of age. Abstinence from alcohol-containing beverages was required for $48 \mathrm{~h}$ prior to study procedures. The research study was approved by the Institutional Review Boards of the JJP VAMC and the KIR. Written informed consent was obtained from each subject prior to study participation.

\section{Procedures}

This was a prospective, open-label, parallel group investigation to differentiate between normal and abnormal testicular function in men with SCI. Baseline screening blood samples were taken from eligible participants to assist in differentiating and grouping those with normal serum testosterone concentrations (eugonadal: $>12.1 \mathrm{nmol}^{-1}$ ) from those with low serum testosterone concentrations (hypogonadal: $\leqslant 12.1 \mathrm{nmol}^{-1}$ ). To determine the differential secretion of testosterone to provocative stimulation, intramuscular hCG was administered at three dose concentrations (that is, 400, 2000 and $4000 \mathrm{IU}$; Novarel, Ferring Pharmaceuticals, Parsippany, NJ, USA). Serial blood draws permitted a dose-response curve to be obtained for each of the three stimulation tests. One of the three dose concentrations was administered each week, with each subject completing 3 consecutive days of testing for each of the hCG doses; hCG was administered intramuscularly on 2 consecutive days with blood collected for serum testosterone between 0800 and 0900 hours prior to each of two injections, with subjects returning on day 3 for a final blood sample collection. The visits between the respective dose administrations were separated by a minimum of 1 week. On average, the participants completed the three-dose visits within a 3-month period. A randomized order was used to administer the dose concentrations. Blood samples from the study visits were centrifuged, and the serum was separated for the determination of testosterone using a commercial kit assay (ICN Biomedicals, Inc., Costa Mesa, CA, USA).
Serum samples were frozen at $-70{ }^{\circ} \mathrm{C}$ until batch processing at the completion of all testing. The serum testosterone concentration was determined in duplicate by radioimmunoassay, in accordance with the manufacturer's guidelines. The sensitivity for the testosterone assay was $3 \mathrm{nmoll}^{-1}$; the intra-assay CV were 9.6, 8.1 and $7.8 \%$ for testosterone concentrations of 3, 24 and $69 \mathrm{nmoll}^{-1}$, respectively; the inter-assay CV were $8.6,9.1$ and $8.4 \%$ for testosterone concentrations of 2,21 and $56 \mathrm{nmol}^{-1}$, respectively; the 2 s.d. normal range for adult males is $9.7-30.5 \mathrm{nmol}^{-1}$.

\section{Statistical analyses}

Values are expressed as group mean \pm s.d. $X^{2}$ tests were performed to determine group differences for categorical variables. $\mathrm{AB}$ and $\mathrm{SCI}$ participants were designated as being Eugonadal or Hypogonadal from the baseline serum testosterone concentration. To aid in statistical comparisons, the primary ( $\mathrm{AB}$ or $\mathrm{SCI}$ ) and gonadal status (Eugonadal or Hypogonadal) group designations were combined to produce a concatenated variable to form four groups: AB-Eugonadal, AB-Hypogonadal, SCI-Eugonadal and SCI-Hypogonadal. Factorial analysis of variance (ANOVA) was performed to identify group differences for demographic (age, height, weight, body mass index (BMI), duration of injury) and baseline testosterone concentrations. To determine whether group differences were present in the stimulated testosterone responses within day $(1,2$ or 3$)$ or between hCG doses $(400,2000$ and 4000 IU), a onefactor three-level (dose) ANOVA with repeated measures on time (Day 1, 2 or 3 ) was performed. A separate repeated measures ANOVA was performed to determine whether the serum testosterone concentrations were different at the respective Day 1 visits for each dose concentration. To further identify and describe significant main effects in the stimulated dose responses, Bonferoni post-hoc tests were applied to the respective time points and group comparisons. An a priori level of significance was set at $P \leqslant 0.05$. Statistical analyses were completed using IBM SPSS Statistics 21 (IBM, Armonk, NY, USA).

\section{RESULTS}

The demographic data for subjects in the AB-Eugonadal, ABHypogonadal, SCI-Eugonadal and SCI-Hypogonadal groups are provided (Table 1). The groups were matched for demographic characteristics, but, by study design, differed for serum testosterone concentration with the SCI-hypogonadal and AB-hypogonadal groups having significantly reduced concentrations compared with their respective Eugonadal group (Table 1).

\section{hCG Provocative stimulation}

Provocative stimulation with hCG was performed at three doses; each dose of hCG was administered twice with blood collection over 3 consecutive days (Figure 1). Day-1 serum testosterone concentrations

Table 1 Characteristics of the study groups

\begin{tabular}{|c|c|c|c|c|c|}
\hline & \multicolumn{2}{|c|}{ Spinal cord injury } & \multicolumn{3}{|c|}{ Able-bodied } \\
\hline & Eugonadal & Hypogonadal & Eugonadal & Hypogonadal & P-value \\
\hline Age (years) & $33 \pm 7$ & $41 \pm 10$ & $36 \pm 7$ & $36 \pm 9$ & 0.06 \\
\hline Height (m) & $1.79 \pm 0.08$ & $1.78 \pm 0.07$ & $1.82 \pm 0.10$ & $1.76 \pm 0.08$ & NS \\
\hline Weight (kg) & $88.1 \pm 20.1$ & $81.7 \pm 15.2$ & $87.6 \pm 11.3$ & $83.6 \pm 14.0$ & NS \\
\hline Paraplegia/tetraplegia (n) & $11 / 5$ & $10 / 4$ & - & - & NS \\
\hline Total testosterone $\left(\mathrm{nmol} \mathrm{I}^{-1}\right)$ & $17.4 \pm 4.4$ & $7.4 \pm 3.8^{a, b}$ & $16.7 \pm 4.3$ & $7.7 \pm 2.3^{\mathrm{c}, \mathrm{d}}$ & $<0.0001$ \\
\hline
\end{tabular}

Abbreviations: AB, able-bodied; BMI, body mass index; DOI, duration of injury; NS, not significant; SCl, spinal cord injury.

The data are presented as group mean \pm s.d.

a $P<0.0001$ : SCl-Eugonadal vs. SCl-Hypogonadal.

${ }^{\mathrm{b}} P<0.0001$ : SCl-Eugonadal vs. AB-Hypogonadal.

${ }^{c} P<0.0001$ : AB-Eugonadal vs. SCl-Hypogonadal.

${ }^{\mathrm{d}} P<0.0001$ : AB-Eugonadal vs. SCl-Hypogonadal. 


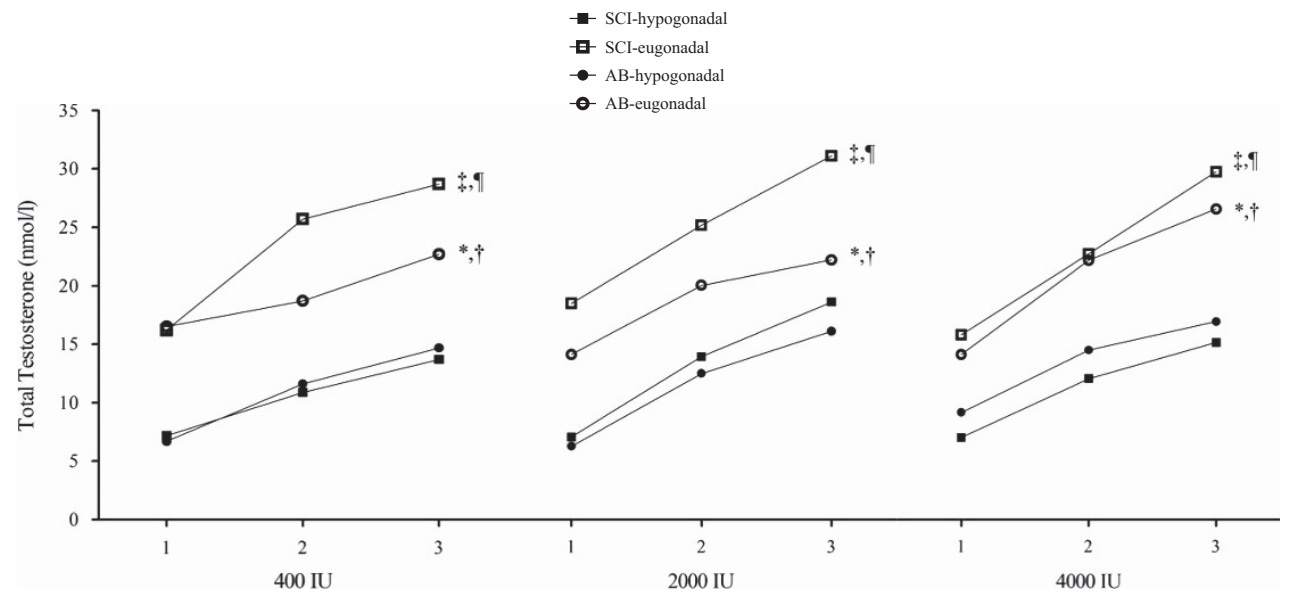

Figure 1 Serum testosterone responses to stimulation by hCG at 400, 2000 and $4000 \mathrm{IU}$. The data are presented as group mean with s.d. bars redacted for enhanced visualization of group serum testosterone responses. s.d. is provided by dose (that is, 400, 2000 and 4000 IU) and Day (that is, 1, 2 and 3 ) in each group for serum testosterone concentrations [(400 IU- AB-Eugonadal: 9.0, 8.6, $6.7 \mathrm{nmol}$ I-1; $^{-1}$ AB-hypogonadal: 3.3, 4.5, $6.5 \mathrm{nmol} \mathrm{I}^{-1}$; SCl-eugonadal: 6.2, 8.6, $9.5 \mathrm{nmol} \mathrm{I}^{-1}$; SCl-hypogonadal: 3.8, 6.8, $6.1 \mathrm{nmolI}^{-1}$ ); (2000 IU- AB-Eugonadal: 4.5, 5.2, $7.5 \mathrm{nmol} \mathrm{I}^{-1}$; AB-hypogonadal: 3.0, 4.5, $6.6 \mathrm{nmol} \mathrm{I}^{-1}$; SCl-eugonadal: 7.7, 8.2, $12.4 \mathrm{nmol} \mathrm{I}^{-1}$; SCI-hypogonadal: 5.2, 6.2, $10.4 \mathrm{nmol}^{-1}$ ); and (4000 IU-AB-Eugonadal: 6.8, $8.6,10.5 \mathrm{nmol} \mathrm{I}^{-1}$; AB-Hypogonadal: 5.1, 8.6, $8.6 \mathrm{nmol}^{-1}$; SCl-eugonadal: 8.7, 7.2, $8.3 \mathrm{nmol} \mathrm{I}^{-1}$; SCI-hypogonadal: 5.2, 5.7, $7.7 \mathrm{nmol} \mathrm{I}^{-1}$ )]). The omnibus statistical models at each dose were statistically significant for group and time main effects, but no group by time interaction was observed. ${ }^{*} P<0.01$ : $\mathrm{SCl}$-eugonadal vs $\mathrm{SCl}$ hypogonadal; ${ }^{\dagger} P<0.01$ : SCl-eugonadal vs $\mathrm{AB}$-hypogonadal; ${ }^{\ddagger} P<0.01$ : AB-eugonadal vs $\mathrm{SCl}$-hypogonadal; ${ }^{\uparrow} P<0.01$ : AB-eugonadal vs $\mathrm{AB}$-hypogonadal.

— that is, prior to each of the three hCG doses - were not significantly different within the Eugonadal and Hypogonadal groups. The serum testosterone concentration increased significantly for each group regardless of the dose of hCG (that is, 400, 2000 and 4000 IU). Within each group, the magnitude of the response of the serum testosterone concentration across the doses of hCG was similar. In all groups, the highest serum testosterone concentrations were observed by Day 3 of each hCG dose. Although the AB-Eugonadal and SCI-eugonadal groups had statistically greater absolute serum testosterone responses than each of the Hypogonadal groups (Figure 1), the average serum testosterone response above baseline for each of the three doses of hCG within and between the Eugonadal groups, and the Hypogonadal groups was not significantly different. The mean serum testosterone concentration post stimulation in both Hypogonadal groups exceeded the lower limit of normal (for example, $>12.1 \mathrm{nmol}^{-1}$ ). Of note, not all subjects in the Hypogonadal groups exceeded the lower limit of normal for the response of serum testosterone concentration at each one of the three doses of hCG: at the $400 \mathrm{IU}$ dose, 3 of 14 SCI-Hypogonadal subjects had values less than the lower limit of normal for testosterone, as did 11 of $27 \mathrm{AB}$ Hypogonadal subjects; at the 2000 IU dose, 5 of 27 SCI-Hypogonadal subjects had values less than the lower limit of normal for testosterone, as did 5 of 27 AB-hypogonadal subjects; at the $4000 \mathrm{IU}$ dose, 3 of 14 SCI-Hypogonadal subjects had values less than the lower limit of normal for testosterone, as did 7 of 27 AB-Hypogonadal subjects. All subjects, in all groups responded with an adequate rise in serum testosterone concentration to one or more of the three doses of hCG. An exploratory post-hoc analysis failed to identify a demographic characteristic (that is, age, weight, BMI, or in SCI, duration of injury) associated with subjects who failed to raise serum testosterone levels into the normal range after provocative stimulation.

\section{DISCUSSION}

Circulating testosterone concentrations have long been of interest to physicians caring for men with SCI because of well-appreciated problems with fertility and impotence, ${ }^{5,18-25}$ as well as the global effects on function and quality of life. Primary testicular and/or central dysfunction may lead to impaired spermatogenesis and infertility. ${ }^{26-30}$ In the general population, primary testicular failure is responsible for the majority of patients with male infertility; about half of these cases have no apparent etiology. ${ }^{30}$ Testosterone is also the major anabolic hormone in adult men. A deficiency of testosterone may be expected to have adverse effects on bone, soft tissue body composition, exercise tolerance and psychological well-being. ${ }^{6-8,31}$

Serum testosterone concentrations have been reported to be depressed in persons with chronic SCI. ${ }^{1-4}$ Testicular failure of primary or secondary origin may be due to one or more etiologies (for example, chronic illness, emotional stress, nutritional factors, medications and local thermal gonadal conditions). ${ }^{9-11,32-38}$ In this study, we hypothesized that by performing graded stimulation of the testes, a more subtle dysfunction of the Leydig cell, if present, may be revealed. Of note, the average response of SCI and $\mathrm{AB}$ participants, regardless of group affiliation by baseline testicular function (for example, eugonadal or hypogonadal), was not significantly different. This finding supports and extends an earlier finding by our group that the testicular response to stimulation with a standard dose of hCG was generally appropriate. It should be mentioned that a minority of participants in each of the hypogonadal and eugonadal groups, regardless of whether $\mathrm{SCI}$ or $\mathrm{AB}$, failed to raise serum testosterone concentrations into the normal range after administration of each of the three doses of hCG. As such, not all subjects with SCI can unequivocally be stated to have an absence of end-organ dysfunction. The finding that hCG did not stimulate the testes to release testosterone into the normal range after each dose of hCG in those with SCI may merely represent chronic hypo-stimulation of the end organ by gonadotropins of the testes, lacking the ability to respond adequately to a relatively short course of provocative stimulation. However, a primary end-organ disorder may also be considered.

Gonadal release of testosterone by Leydig cells is under the regulation of the pituitary gland, and, more specifically, the episodic, pulsatile release of luteinizing hormone. In the classic feedback loop, if an individual has primary testicular failure, serum testosterone levels are depressed and plasma luteinizing hormone levels are elevated. Indeed, some investigators have reported elevated basal or stimulated 
levels of plasma luteinizing hormone when serum testosterone levels are low in cohorts of subjects with SCI. ${ }^{39-41}$ However, as in our report herein, other investigators have reported in persons with SCI that the basal levels of plasma luteinizing hormone were not elevated despite the presence of depressed serum testosterone concentrations. ${ }^{12,42,43}$ As previously discussed, a subset of our hypogonadal subjects with SCI did not have adequate responses to one or more doses of hCG. Indeed, individuals with such a hormonal picture (for example, hypogonadal with normal basal plasma luteinizing hormone levels) may represent a heterogeneous group of individuals with a mixture of central and/or peripheral dysfunction, as determined by a variety of pituitary and gonadal stimulation tests in an $\mathrm{AB}$ population. ${ }^{44}$

It is intriguing to consider the possibility that feedback from the testes could influence central gonadotropin function, and hence testicular function. Inhibin is a gonadal peptide that suppresses follicular stimulating hormone release and acts to regulate the function of the pituitary-gonadal axis. ${ }^{45,46}$ Inhibin $\mathrm{B}$ is the predominant circulating and centrally active form that is also accepted as a marker of Sertoli cell function, ${ }^{47}$ and levels of inhibin have a diurnal variation in normal men, with a reduction of levels reported with advancing age. ${ }^{48,49}$ With interruption of nervous innervation to the testes, it is likely that the normal diurnal patterns for both testosterone and inhibin are absent, with possible adverse central consequences on gonadotropin regulation. The hypothesized central dysregulation may result by interfering with the normal stimulatory effect of activins both on follicular stimulating hormone release, thus possibly decreasing hormone levels, and on gonadotropin-releasing hormone receptor concentration in the basal and stimulated states, ${ }^{50,51}$ decreasing receptor availability, and by doing so, modulating gonadotrope sensitivity to gonadotropin-releasing hormone.

In an earlier article by our group, the pituitary-testicular axis was evaluated by the administration of conventional gonadotropinreleasing hormone stimulation test of the pituitary and hCG stimulation test of the gonads. ${ }^{13}$ An exaggerated gonadotropin response of the pituitary gland to provocative stimulation may suggest end-organ dysfunction; however, in the majority of subjects, the testes responded normally to stimulation, regardless of whether the participants were eugonadal or hypogonadal; as such, the possibility of diminished hypothalamic drive to the pituitary was raised as the most likely alternative explanation. ${ }^{13}$ The authors concluded that a disorder of the hypothalamic-pituitary axis was indeed present, but it was suggested that a graded provocative stimulation of the testes may be worthwhile to perform in an effort to unmask a more subtle deficit in end-organ function. The work presented herein suggests that, even after provocative testing at two lower doses of hCG, testicular function was generally normal in a cohort of men with SCI, regardless of baseline gonadal status.

\section{CONCLUSION}

Stimulation of the testes with hCG in an incremental manner in men with SCI demonstrated a normal response of testosterone, regardless of baseline gonadal status. This finding adds support to the prior work that suggested a secondary testicular failure, likely hypothalamic in origin, is present in a majority of those with depressed serum testosterone concentrations. However, because not all subjects responded appropriately to gonadal stimulation at each dose of hCG administered, the SCI population may also have a minority of individuals with impaired testicular function that may be partially or wholly responsible for depressed levels of serum testosterone.

\section{DATA ARCHIVING}

There were no data to deposit.

\section{CONFLICT OF INTEREST}

The authors declare no conflict of interest.

\section{ACKNOWLEDGEMENTS}

The authors thank the James J Peters VA Medical Center, Bronx, NY, USA, and the Kessler Institute for Rehabilitation, West Orange, NJ, USA for their support. This work was supported by the Department of Veterans Affairs, Veterans Health Administration, Rehabilitation Research \& Development Service by funding through the National Center for the Medical Consequences of Spinal Cord Injury (B2648-C, B4162-C \& B9212-C, and B2020-C).

1 Bauman WA, La Fountaine MF, Spungen AM. Age-related prevalence of low testosterone in men with spinal cord injury. J Spinal Cord Med 2014; 37: 32-39.

2 Clark MJ, Schopp LH, Mazurek MO, Zaniletti I, Lammy AB, Martin TA et al. Testosterone levels among men with spinal cord injury: relationship between time since injury and laboratory values. Am J Phys Med Rehabil 2008; 87: 758-767.

3 Durga A, Sepahpanah F, Regozzi M, Hastings J, Crane DA. Prevalence of testosterone deficiency after spinal cord injury. PMR 2011; 3: 929-932.

4 Schopp LH, Clark M, Mazurek MO, Hagglund KJ, Acuff ME, Sherman AK et al. Testosterone levels among men with spinal cord injury admitted to inpatient rehabilitation. Am J Phys Med Rehabil 2006; 85: 678-684.

5 Naderi AR, Safarinejad MR. Endocrine profiles and semen quality in spinal cord injured men. Clin Endocrinol 2003; 58: 177-184.

6 Tenover JL. Therapeutic perspective: Issues in testosterone replacement in older men. Can replacement doses of testosterone produce clinically meaningful changes in body composition in older men? J Clin Endocrinol Metab 1998; 83: 3439-3440.

7 Auyeung TW, Lee JS, Kwok T, Leung J, Ohlsson C, Vandenput L et al. Testosterone but not estradiol level is positively related to muscle strength and physical performance independent of muscle mass: a cross-sectional study in 1489 older men. Eur J Endocrinol 2011; 164: 811-817.

8 Hintikka J, Niskanen L, Koivumaa-Honkanen H, Tolmunen T, Honkalampi K, Lehto SM et al. Hypogonadism, decreased sexual desire, and long-term depression in middleaged men. J Sex Med 2009; 6: 2049-2057.

9 Gray A, Feldman HA, McKinlay JB, Longcope C. Age, disease, and changing sex hormone levels in middle-aged men: results of the Massachusetts Male Aging Study. J Clin Endocrinol Metab 1991; 73: 1016-1025.

10 Friedl KE, Moore RJ, Hoyt RW, Marchitelli LJ, Martinez-Lopez LE, Askew EW. Endocrine markers of semistarvation in healthy lean men in a multistressor environment. J Appl Physiol (1985) 2000; 88: 1820-1830.

11 Isidori AM, Lenzi A. Risk factors for androgen decline in older males: lifestyle, chronic diseases and drugs. J Endocrinol Invest 2005; 28(3 Suppl): 14-22.

12 Daniell HW. Hypogonadism in men consuming sustained-action oral opioids. J Pain 2002; 3: 377-384.

13 Bauman WA, La Fountaine MF, Cirnigliaro CM, Kirshblum SC, Spungen AM. Provocative stimulation of the hypothalamic-pituitary-testicular axis in men with spinal cord injury. Spinal Cord 2016; 54: 961-966.

14 Padron RS, Wischusen J, Hudson B, Burger HG, de Kretser DM. Prolonged biphasic response of plasma testosterone to single intramuscular injections of human chorionic gonadotropin. J Clin Endocrinol Metab 1980; 50: 1100-1104.

15 Smals AG, Pieters GF, Drayer JI, Benraad TJ, Kloppenborg PW. Leydig cell responsiveness to single and repeated human chorionic gonadotropin administration. J Clin Endocrinol Metab 1979; 49: 12-14.

16 Okuyama A, Namiki M, Koide T, Itatani H, Mizutani S, Sonoda T et al. A simple hCG stimulation test for normal and hypogonadal males. Arch Androl 1981; 6: 75-81.

17 Forest MG, Lecoq A, Saez JM. Kinetics of human chorionic gonadotropin-induced steroidogenic response of the human testis. II. Plasma 17 alpha-hydroxyprogesterone, delta4-androstenedione, estrone, and 17 beta-estradiol: evidence for the action of human chorionic gonadotropin on intermediate enzymes implicated in steroid biosynthesis. J Clin Endocrinol Metab 1979; 49: 284-291.

18 Brackett NL, Lynne CM, Weizman MS, Bloch WE, Abae M. Endocrine profiles and semen quality of spinal cord injured men. J Urol 1994; 151: 114-119.

19 Munro D, Horne HW Jr, Paull DP. The effect of injury to the spinal cord and cauda equina on the sexual potency of men. N Engl J Med 1948; 239: 903-911.

20 Horne HW, Paull DP, Munro D. Fertility studies in the human male with traumatic injuries of the spinal cord and cauda equina. N Engl J Med 1948; 239: 959-961.

21 Bors E, Engle ET, Rosenquist RC, Holliger VH. Fertility in paraplegic males; a preliminary report of endocrine studies. J Clin Endocrinol Metab 1950; 10: 381-398.

22 Ver Voort SM. Infertility in spinal-cord injured male. Urology 1987; 29: 157-165.

23 Beretta G, Chelo E, Zanollo A. Reproductive aspects in spinal cord injured males. Paraplegia 1989; 27: 113-118.

24 Linsenmeyer TA. Male infertility following spinal cord injury. J Am Paraplegia Soc 1991; 14: $116-121$ 
25 Huang HF, Li MT, Giglio W, Anesetti R, Ottenweller JE, Pogach LM. The detrimental effects of spinal cord injury on spermatogenesis in the rat is partially reversed by testosterone, but enhanced by follicle-stimulating hormone. Endocrinology 1999; 140: 1349-1355.

26 Meeker JD, Godfrey-Bailey L, Hauser R. Relationships between serum hormone levels and semen quality among men from an infertility clinic. J Androl 2007; 28: 397-406.

27 Sina D, Schuhmann R, Abraham R, Taubert HD, Dericks-Tan JS. Increased serum FSH levels correlated with low and high sperm counts in male infertile patients. Andrologia 1975; 7: 31-37.

28 Subhan F, Tahir F, Ahmad R, Khan ZD. Oligospermia and its relation with hormonal profile. JPMA J Pak Med Associ 1995; 45: 246-247.

29 Jensen TK, Andersson AM, Jorgensen N, Andersen AG, Carlsen E, Petersen JH et al. Body mass index in relation to semen quality and reproductive hormones among 1558 Danish men. Fertil Steril 2004; 82: 863-870.

30 Krausz C. Male infertility: pathogenesis and clinical diagnosis. Best Pract Res Clin Endocrinol Metab 2011; 25: 271-285.

31 Storer TW, Woodhouse L, Magliano L, Singh AB, Dzekov C, Dzekov J et al. Changes in muscle mass, muscle strength, and power but not physical function are related to testosterone dose in healthy older men. J Am Geriatr Soc 2008; 56: 1991-1999.

32 Tuck SP, Francis RM. Testosterone, bone and osteoporosis. Front Horm Res 2009; 37 123-132.

33 Finkelstein JS, Yu EW, Burnett-Bowie SA. Gonadal steroids and body composition, strength, and sexual function in men. N Eng/ J Med 2013; 369: 2457.

34 Bhasin S, Storer TW, Berman N, Callegari C, Clevenger B, Phillips J et al. The effects of supraphysiologic doses of testosterone on muscle size and strength in normal men. N Engl J Med 1996; 335: 1-7.

35 Snyder PJ, Bhasin S, Cunningham GR, Matsumoto AM, Stephens-Shields AJ, Cauley JA et al. Effects of testosterone treatment in older men. N Engl J Med 2016; 374: 611-624.

36 Cherrier MM, Anderson K, Shofer J, Millard S, Matsumoto AM. Testosterone treatment of men with mild cognitive impairment and low testosterone levels. Am J Alzheimers Dis Other Demen 2015; 30: 421-430.

37 Smith HS, Elliott JA. Opioid-induced androgen deficiency (OPIAD). Pain Physician 2012; 15(3 Suppl): ES145-ES156.
38 Rubinstein A, Carpenter DM. Elucidating risk factors for androgen deficiency associated with daily opioid use. Am J Med 2014; 127: 1195-1201.

39 Perkash I, Martin DE, Warner H, Blank MS, Collins DC. Reproductive biology of paraplegics: results of semen collection, testicular biopsy and serum hormone evaluation. J Urol 1985; 134: 284-288.

40 Hayes PJ, Krishnan KR, Diver MJ, Hipkin LJ, Davis JC. Testicular endocrine function in paraplegic men. Clin Endocrinol 1979; 11: 549-552.

41 Huang TS, Wang YH, Chiang HS, Lien YN. Pituitary-testicular and pituitary-thyroid axes in spinal cord-injured males. Metabolism 1993; 42: 516-521.

42 Kikuchi TA, Skowsky WR, El-Toraei I, Swerdloff R. The pituitary-gonadal axis in spinal cord injury. Fertil Steril 1976; 27: 1142-1145.

43 Morley JE, Distiller LA, Lissoos I, Lipschitz R, Kay G, Searle DL et al. Testicular function in patients with spinal cord damage. Horm Metab Res 1979; 11: 679-682.

44 Glass AR. Pituitary-testicular reserve in men with low serum testosterone and norma serum luteinizing hormone. J Androl 1988; 9: 224-230.

45 Gregory SJ, Kaiser UB. Regulation of gonadotropins by inhibin and activin. Semin Reprod Medi 2004; 22: 253-267.

46 Bilezikjian LM, Blount AL, Donaldson CJ, Vale WW. Pituitary actions of ligands of the TGF-beta family: activins and inhibins. Reproduction 2006; 132: 207-215.

47 Iliadou PK, Tsametis C, Kaprara A, Papadimas I, Goulis DG. The Sertoli cell: novel clinical potentiality. Hormones 2015; 14: 504-514.

48 Tenover JS, Bremner WJ. Circadian rhythm of serum immunoreactive inhibin in young and elderly men. J Gerontol 1991; 46: M181-M184.

49 Chong YH, Pankhurst MW, McLennan IS. The daily profiles of circulating AMH and INSL3 in men are distinct from the other testicular hormones, inhibin B and testosterone. PLOS ONE 2015; 10: e0133637.

50 Wang QF, Farnworth PG, Findlay JK, Burger HG. Inhibitory effect of pure 31-kilodalton bovine inhibin on gonadotropin-releasing hormone (GnRH)-induced up-regulation of GnRH binding sites in cultured rat anterior pituitary cells. Endocrinology 1989; 124 363-368.

51 Winters SJ, Pohl CR, Adedoyin A, Marshall GR. Effects of continuous inhibin administration on gonadotropin secretion and subunit gene expression in immature and adult male rats. Biol Reprod 1996; 55: 1377-1382. 